\title{
Commentary: To sew or to stent? That's the question
}

\section{Marek Ehrlich, MD}

Thoracoabdominal aortic aneurysms represent a serious life-threatening situation due to potential of rupture or dissection. Resection and graft replacement of the pathologically altered aorta was for decades the only treatment modality. ${ }^{1-3}$ Although great strides have been achieved during the past 40 years in the management of patients with these aortic conditions by new surgical techniques, intraoperative monitoring of somatosensory-evoked potentials and spinal cord fluid drainage, postoperative morbidity and mortality rates still remain high, especially in older patients. ${ }^{4}$ The affected population presents at the time of operation with various comorbidities such as hypertension, obstructive pulmonary disease, and coronary artery disease, all of which have significant influence on the surgical outcome. Postoperative complications, such as paraplegia as well as renal and pulmonary insufficiency, contribute to prolonged hospital stays and higher medical cost.

Since the first successful endovascular stent graft placement in thoracic aortic aneurysm or dissections, ${ }^{5}$ thoracic endovascular aortic repair (TEVAR) has become a valid treatment modality for a variety of thoracic of aortic pathologies. Endograft systems and the procedure itself have been continuously improved over the past 20 years.

The article by Rocha and colleagues ${ }^{6}$ sheds some important light on the ongoing debate of open aortic surgical repair versus TEVAR. This group from Canada performed a multicenter, population-based propensity scored study with $664 \mathrm{pa}-$ tients across the province of Ontario comparing early and late outcomes of endovascular versus open thoracoabdominal aortic aneurysm repair. Open repair was associated with a higher incidence of in-hospital death, more complications, and longer median length of stay. Long-term mortality was

From the Aneurysm Program, University of Vienna, Vienna, Austria.

Disclosures: The author reported no conflicts of interest.

The Journal policy requires editors and reviewers to disclose conflicts of interest and to decline handling or reviewing manuscripts for which they may have a conflict of interest. The editors and reviewers of this article have no conflicts of interest.

Received for publication April 28, 2020; revisions received April 28, 2020; accepted for publication April 28, 2020; available ahead of print May 12, 2020.

Address for reprints: Marek Ehrlich, MD, Aneurysm Program, University of Vienna, Währinger Gürtel 18-20, 1090 Vienna, Austria (E-mail: marek.ehrlich@ meduniwien.ac.at).

J Thorac Cardiovasc Surg 2021;161:532-3

$0022-5223 / \$ 36.00$

Copyright (c) 2020 by The American Association for Thoracic Surgery

https://doi.org/10.1016/j.jtcvs.2020.04.132

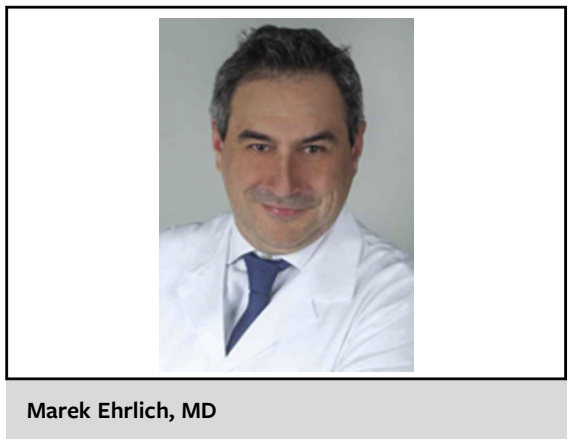

CENTRAL MESSAGE

This study compares open

versus endovascular repair of

TAAA and helps us better un-

derstand the comparative effi-

cacies of these well-established

methods.

not significantly different, with the exception of secondary procedures, which was higher in the endovascular group. However, both groups had disappointing 8-year survival, reflecting associated comorbidities in these patients. Using expert statistical analysis, the authors reveal 3 important findings in this article. First, institutional volume appears to have a substantial effect on mortality following open thoracoabdominal aortic aneurysm, reflecting that these highly complex operations should be performed not only in high volume centers but also by an aortic-repair-specific team. Secondly, like in coronary artery bypass grafting versus percutaneous transluminal coronary angioplasty trials, secondary procedures on the thoracoabdominal aorta or its branches were significantly higher following TEVAR compared with open repair. Thirdly, independent of the repair technique, long-term survival, and adverse events were bleak, reflecting the high burden of comorbidities in this very sick patient population. Limitations, as noted by the authors, were that important unmeasured confounders were not considered. Prognostic factors, including patient characteristics, surgical details, and surgeon experience were also not captured.

This area desperately needs more randomized trials to refine which of these 2 methods is more effective so that we can make smarter decisions regarding the technique to be used and, most of all, which patients should be treated or not.

\section{References}

1. Cooley DA, DeBakey ME. Surgical considerations of intrathoracic aneurysms of the aorta and great vessels. Ann Surg. 1952;135:660-80. 
2. Coselli JS, LeMaire SA, Preventza O, de la Cruz KI, Cooley DA, Price MD, et al. Outcomes of 3309 thoracoabdominal aortic aneruysm repairs. J Thorac Cardiovasc Surg. 2016;141:1232-7.

3. Kouchoukos NT, Kulik A, Castner CF. Open thoracoabdominal repair for chronic type B dissection. J Thorac Cardiovasc Surg. 2015;149(2 Suppl):S125-9.

4. Tanaka A, Leonard SD, Sandhu HK, Afifi RO, Miller CC III, Charlton-Ouw KM, et al. Open descending and thoracoabdominal repairs in patients younger than 50 years old. Ann Thorac Surg. 2019;108:693-9.
5. Dake MD, Miller DC, Semba CP, Mitchell RS, Walker PJ, Liddell RP. Transluminal placement of endovascular stent- grafts for the treatment of descending thoracic aortic aneurysms. N Engl J Med. 1994;331: 329-34.

6. Rocha RV, Lindsay TF, Austin PC, Al-Omran M, Forbes TL, Lee DS, et al. Outcomes after following endovascular versus open thoracoabdominal aortic aneurysm repair: a population-based study. J Thorac Cardiovasc Surg. 2021;161:516-27.e6. 